\title{
Predictors of recurrent ingestion of gastrointestinal foreign bodies
}

\author{
Ian C Grimes $M D^{1}$, Bret J Spier MD¹, Lisa R Swize $M D^{1}$, Mary J Lindstrom PhD², Patrick R Pfau MD ${ }^{1}$
}

IC Grimes, BJ Spier, LR Swize, MJ Lindstrom, PR Pfau. Predictors of recurrent ingestion of gastrointestinal foreign bodies. Can J Gastroenterol 2013;27(1):e1-e4.

BACKGROUND: Gastrointestinal foreign bodies are commonly encountered; however, little knowledge exists as to the causes of foreign body ingestions and why they occur repeatedly in some patients. OBJECTIVE: To identify and define patients at high risk for recurrent foreign body ingestion.

METHODS: A retrospective chart review of foreign body ingestion was conducted at a tertiary care medical centre over an 11-year period. Variables analyzed included age, sex, incarceration status, Diagnostic and Statistical Manual of Mental Disorders-IV diagnosis, success of endoscopy, type of sedation used, method of extraction, complications, presence of gastrointestinal pathology, and incidence of recurrent food impaction or foreign body.

RESULTS: A total of 159 patients with a foreign body ingestion were identified. One hundred fourteen $(77 \%)$ experienced a single episode of ingestion and 45 (23\%) experienced multiple ingestions. Of the patients with multiple ingestions, 27 (60\%) had recurrent food impactions while 18 (40\%) ingested foreign objects. In the recurrent ingestor group, a psychiatric disorder had been diagnosed in 16 patients $(35.6 \%)$ and there were 13 incarcerated individuals (28.9\%). The average number of recurrences was 2.6 per patient (117 total recurrences). Individuals with a psychiatric disorder experienced 3.9 recurrences per patient, while prisoners averaged 4.1 recurrences per patient. The combination of a psychiatric disorder and being incarcerated was associated with the highest recurrence rate ( 4.33 per patient). Multivariable logistic regression revealed that male sex $(\mathrm{OR} 2.9 ; \mathrm{P}=0.022)$, being incarcerated $(\mathrm{OR} 3.0 ; \mathrm{P}=0.024)$ and the presence of a psychiatric disor$\operatorname{der}(\mathrm{OR} 2.5 ; \mathrm{P}=0.03)$ were risk factors for recurrent ingestion.

CONCLUSION: Risk factors for recurrent ingestion of foreign bodies were male sex, being incarcerated and the presence of a psychiatric disorder.

Key Words: Foreign body; Recurrent esophageal impaction

\section{Les prédicteurs d'ingestion récurrente de corps étrangers dans le tractus gastro-intestinal}

HISTORIQUE : On trouve souvent des corps étrangers dans le tractus
gastro-intestinal, mais on ne sait pas grand-chose des causes de ces inges-
tions et de la raison de leur survenue à répétition chez certains patients.
OBJECTIF : Déterminer et définir les patients à haut risque d'ingestion
récurrente de corps étranger. MÉTHODOLOGIE : Les chercheurs ont procédé à une analyse rétrospective des dossiers d'ingestion de corps étrangers dans un centre de soins tertiaires sur une période de 11 ans. Ils ont analysé les variables de l'âge, du sexe et de la situation d'incarcération, du diagnostic selon la quatrième édition du Manuel diagnostique et statistique des troubles mentaux, de la réussite de l'endoscopie, du type de sédation utilisée, du mode d'extraction, des complications, de la présence d'une pathologie gastro-intestinale et de l'incidence d'impaction alimentaire ou d'ingestion de corps étranger à répétition.

RÉSULTATS : Au total, les chercheurs ont repéré 159 patients ayant ingéré un corps étranger. Cent quatorze (77\%) avaient vécu un seul épisode et 45 (23\%), de multiples épisodes. Sur les patients qui avaient vécu de multiples épisodes, 27 (60\%) présentaient une impaction alimentaire récurrente, tandis que 18 (40\%) avaient ingéré des corps étrangers. Dans le groupe ayant ingéré des corps étrangers à répétition, on a diagnostiqué un trouble psychiatrique chez 16 patients $(35,6 \%)$, et 13 individus étaient incarcérés $(28,9 \%)$. On constatait un nombre moyen de récurrences de 2,6 cas par patient (total de 117 récurrences). Les patients ayant un trouble psychiatrique avaient vécu une moyenne de 3,9 récurrences, et les prisonniers, une moyenne de 4,1 récurrences. La combinaison d'un trouble psychiatrique et d'une incarcération s'associait au taux de récurrence le plus élevé (4,33 par patient). La régression logistique multivariable a révélé que le sexe masculin (RRR 2,9; $\mathrm{P}=0,022$ ), l'incarcération (RRR 3,0; $\mathrm{P}=0,024$ ) et la présence d'un trouble psychiatrique ( $R R R 2,5 ; P=0,03)$ étaient des facteurs de risque d'ingestion récurrente.

CONCLUSION : Les facteurs de risque d'ingestion récurrente de corps étrangers étaient le sexe masculin, l'incarcération et la présence d'un trouble psychiatrique.

Currently, the overwhelming majority of foreign body literature is descriptive (types and location of foreign bodies) and there is a paucity of literature attempting to identify individuals at risk for recurrent foreign body ingestion. If a specific population could be identified as 'high risk for recurrence', then certain measures could be directed at preventing another ingestion event. Thus, the primary aim of our study was to identify predictors of recurrent ingestion among a retrospective cohort of patients presenting with GI foreign bodies.

Study design

\section{METHODS}

The University of Wisconsin Hospital and Clinics (Madison, Wisconsin, USA) is the major tertiary care centre for the state of Wisconsin, with $>43,000$ emergency department visits per year, and the main referral centre for the Wisconsin state prison system. Patients eously without clinical sequelae (1). However, $10 \%$ to $20 \%$ of GI foreign bodies require endoscopic intervention $(9-11)$.

${ }^{1}$ Department of Medicine; Division of Gastroenterology and Hepatology; ${ }^{2}$ Department of Biostatistics and Medical Informatics, University of Wisconsin Hospital and Clinics, Madison, Wisconsin, USA.

Correspondence: Dr Patrick R Pfau, Division of Gastroenterology and Hepatology, University of Wisconsin Hospital and Clinics, 4241 MFCB,

1685 Highland Avenue, Madison, Wisconsin 53705, USA. Telephone 608-263-4033, e-mail prp@medicine.wisc.edu

Received for publication January 13, 2012. Accepted August 12, 2012 
TABLE 1

Univariable analysis comparing single ingestors and recurrent ingestors ( $n=117$ endoscopies)

\begin{tabular}{|c|c|c|c|c|}
\hline & \multicolumn{2}{|c|}{ Ingestors } & \multirow[b]{2}{*}{$\mathrm{OR}^{*}(95 \% \mathrm{Cl})$} & \multirow[b]{2}{*}{$\mathbf{P}^{*}$} \\
\hline & Single $(n=114)$ & Recurrent $(n=45)$ & & \\
\hline Age, years, mean (range) & $50.7(19-92)$ & $45.2(18-94)$ & - & 0.139 \\
\hline Male sex & $67 / 114$ & $38 / 45$ & $3.8(1.5-10.9)$ & 0.003 \\
\hline Prisoner & $10 / 114$ & $13 / 45$ & $4.2(1.5-11.8)$ & 0.002 \\
\hline Esophageal pathology & $73 / 114$ & $22 / 45$ & $0.5(0.2-1.1)$ & 0.072 \\
\hline Successful endoscopy & $111 / 114$ & $104 / 117$ & $1.2(0-63.8)$ & 0.999 \\
\hline Use of conscious sedation & $105 / 114$ & $104 / 117$ & $0.7(0.2-2.8)$ & 0.541 \\
\hline Complications & $2 / 114$ & $2 / 117$ & $0(0-13.6)$ & 0.999 \\
\hline Need for surgery & $1 / 114$ & $4 / 117$ & $0(0-98.6)$ & 0.999 \\
\hline Follow-up, days, median (range) & $19.5(1-64)$ & $71.0(22-101)$ & - & 0.255 \\
\hline
\end{tabular}

Data presented as $n / n$ unless otherwise indicated. *ORs and $P$ values calculated using two-sample Wilcoxon and Fisher's exact tests based on patient-level data

$>18$ years of age with foreign body ingestions who presented to the University of Wisconsin Hospital and Clinics between December 1996 and February 2008 were identified. Patients were identified using International Classification of Diseases, Ninth Revision codes for foreign bodies (codes 937, 935.1, 938, 936 and 935.2), which included both the upper and lower GI tract. Once patients were identified through administrative data, a formal chart review was performed. The endoscopy database was used to review each procedure in full. A full review of the medical record was also performed on each patient, and included clinic notes, endoscopy reports and radiology records. The present study was reviewed and approved by the institutional review board.

\section{Variables collected}

Patient characteristics including age at time of ingestion, sex, incarceration status at time of ingestion, and the presence of an existing or active 'psychiatric disorder' as defined by the Diagnostic and Statistical Manual of Mental Disorders (DSM)-IV criteria of psychiatric disorders were collected. The DSM-IV covers all mental health disorders for children and adults, including depression, anxiety, substance abuse and schizophrenia. Any psychiatric or substance abuse disorder was recorded.

Procedural data, including success of endoscopy, type of sedation used, method of extraction and immediate procedure-related complications, were recorded. Additional data collected included findings of gastroesophageal pathology (ie, stricture or tumour) and specific foreign body if other than food impaction. If endoscopy proved to be unsuccessful, the ultimate need for surgery was recorded. Postendoscopy follow-up and number of recurrences were recorded.

Foreign bodies were further subdivided into categories of food impaction and ingested foreign object.

\section{Statistical analysis}

For statistical analysis, the data were reduced to a single data point per patient. This avoided the problem of within-patient correlation; little information was lost because most variables were constant within an individual. The classification variables that did vary according to occurrence were performance of successful endoscopy, use of conscious sedation, complication rate and type of obstruction. A maximum of six of 159 patients had multiple values for these variables; the most frequently occurring value was chosen. Two other variables that varied according to occurrence within a patient were the continuous variables age and length of follow-up, which were averaged within a patient.

To assess the relationship between each variable and recurrence status, Fisher's exact tests for the classification variables and Wilcoxon tests for the continuous variables were used. Multivariable, stepwise, logistic regression based on minimizing the Akaike Information Criterion (an information criterion) was used to deterrmine the most important predictor variables for recurrence. Both forward and backward elimination were used.

\section{Patient characteristics}

\section{RESULTS}

The study population consisted of 159 patients (105 [66\%] men; 54 [34\%] women) with a foreign body ingestion diagnosed over an 11 -year period (Table 1).

There were 114 single ingestors (67 [59\%] men; 38 [41\%] women) with a mean age of 50.7 years (range 19 to 92 years). Of the 114 patients who only had one recorded foreign body at the University of Wisconsin Hospital and Clinics, 77 (68\%) had food impactions, while $37(32 \%)$ ingested true foreign objects. A psychiatric disorder had been diagnosed in 18 patients $(15.8 \% ; 14$ men, four women). There were 10 prisoners $(8.8 \%)$ in this group, nine $(90 \%)$ of whom had ingested a foreign object.

There were 45 recurrent ingestors (38 [84\%] men; seven [16\%] women) with a mean age of 45.2 years (range 18 to 94 years) Of the 45 patients who had more than one GI foreign body, there were $54(46 \%)$ endoscopies performed for food impactions, while 63 (54\%) endoscopies were performed for ingested true foreign objects. A psychiatric disorder had been diagnosed in 16 patients (35.6\%: 14 men; two women). There were 13 prisoners (28.9\%) in the group of patients with recurrent food bolus ingestions. The average number of recurrences was 2.6 per patient (117 total recurrences). Individuals with a psychiatric disorder experienced a mean of 3.9 recurrent ingestions each, while prisoners averaged 4.1 recurrences each. The combination of a psychiatric disorder and incarcerated status had the highest recurrence rate ( 4.33 per patient).

Sixty per cent (27 of 45$)$ of the patients with repeat ingestions experienced recurrent food impactions. Of these patients, 21 (78\%) had esophageal pathology. The most common type of pathology was a distal esophageal stricture (62\%), six (29\%) had pathology related to carcinoma and other pathology included a lye-induced stricture and one confirmed case of eosinophilic esophagitis leading to a diffuse esophageal structuring with rings.

\section{Procedural data}

Of the 114 single ingestors who underwent endoscopy with an indication of foreign body, 87 procedures identified the foreign body in the esophagus, 18 in the stomach and nine in other locations (rectum $[n=4]$, duodenum [n=3], appendix $[n=1]$ and sigmoid colon $[n=1])$. Conscious sedation was used in 105 (92\%) cases, with the remainder of the procedures performed using general anesthesia. Endoscopy was successful in 111 (97\%) cases and, on one occasion, surgery was required.

In the patient population with recurrent ingestion, a total of 117 endoscopies were performed for the indication of foreign body, 53 procedures identified the foreign body in the esophagus, 59 in the stomach and five in other locations (duodenum $[n=2]$, rectum $[n=1]$, sigmoid colon $[n=1]$ and ileocecal valve $[n=1])$. Conscious sedation 
TABLE 2

Foreign objects found at endoscopy

\begin{tabular}{lc}
\hline Object & $\mathbf{n}$ \\
\hline Food & 115 \\
Toothbrush & 21 \\
Pencil & 18 \\
Pen & 17 \\
Spoon & 15 \\
Toothpaste tube & 13 \\
Antenna & 10 \\
Plastic & 10 \\
Comb & 8 \\
Shoe fragments & 5 \\
Razor blades & 4 \\
Glasses & 4 \\
Rubber & 2 \\
Metal fragments & 2 \\
Nail & 2 \\
Nail clippers & 2 \\
Dental piece & 2 \\
Intavenous tubing & 2 \\
Miscellaneous (occurring one time) & 20 \\
\hline
\end{tabular}

was used in 104 (89\%) cases, with 11\% needing general anesthesia for their endoscopic procedure. Endoscopy was successful in 104 (88\%) cases. Four of the 13 patients with failed attempts at endoscopic removal eventually required surgery. The remainder of the cases experienced spontaneous passage of the foreign body after a period of observation.

Specific findings at the time of endoscopy and methods used for foreign object retrieval \{removal?\} are shown in detail in Tables 2 and 3.

\section{Comparisons between single and recurrent ingestors}

The univariate analysis identified male sex $(\mathrm{P}=0.003)$, the presence of a psychiatric disorder $(\mathrm{P}=0.009)$ and being a prisoner $(\mathrm{P}=0.002)$ as significant risk factors for recurrent foreign body ingestion (Table 1). In addition, endoscopy was more successful in the single ingestor group $(\mathrm{P}=0.017)$ compared with the recurrent ingestors. True foreign objects (versus food impaction) were more likely encountered in the recurrent ingestor group $(\mathrm{P}=0.0014)$ when compared with the single ingestors. Complications, the use of conscious sedation (or need for general anesthesia), esophageal pathology and age were not significant predictors of recurrent ingestion.

The multiple stepwise logistic regression analysis produced a model with two terms: male sex (OR 2.9; $\mathrm{P}=0.022)$; and prisoner status ( $\mathrm{OR}$ 3.0; $\mathrm{P}=0.0248)$. Psychiatric disorder can be substituted for prisoner status (OR 2.5; $\mathrm{P}=0.030$ ) with almost equal probability.

\section{DISCUSSION}

Foreign body ingestions are a common problem in gastoenterology clinical practice. The large majority of patients with foreign body ingestions do not require intervention and objects pass spontaneously (1). However, $10 \%$ to $20 \%$ of GI foreign bodies will require endoscopic intervention and 1\% may require surgical intervention (9-11). Because a significant number will require procedures, it is important to understand how ingested foreign bodies result in significant disease and which patients are more likely to ingest complex foreign bodies. Furthermore, complex and multiple objects are often seen in patients who intentionally ingest foreign bodies, particularly patients with psychiatric illnesses or incarcerated patients who often ingest razor blades, pins, needles, nails, writing instruments and metal wires. Yet, despite a plethora of data detailing the types and location of foreign bodies ingested, there are limited data detailing the groups at risk for intentional ingestion. In a small study of 36 patients, O'Sullivan et al (7) demonstrated that certain subgroups, such as prisoners and those
TABLE 3

Devices/techniques used for endoscopic removal of ingested foreign bodies

\begin{tabular}{lc}
\hline Device/technique & $\mathbf{n}$ \\
\hline Push technique & 95 \\
Snare & 80 \\
Overtube & 26 \\
Retrieval net & 22 \\
Rat-tooth forceps & 19 \\
Biopsy forceps & 9 \\
Colonoscopy & 3 \\
Flexible sigmoidoscopy & 3 \\
Fluoroscopic guidance & 2 \\
Mesh basket & 1 \\
Suction forceps & 1 \\
Water irrigation & 1 \\
Pediatric colonoscope & 1 \\
Suction & 1 \\
Anoscope & 1 \\
Transnasal gastroscopy & 1 \\
\hline
\end{tabular}

with psychiatric illness, had a higher frequency of foreign body ingestion. Lee et al (12) also reported on the unusual, complex ingestions in a prison population. More recently, Palta et al (13) examined a group of patients from an urban health care setting, with almost all intentional ingestions in $85 \%$ of whom had a psychiatric disease. However, there is no literature describing risk factors for repetitive foreign body ingestion, thus, prompting the primary aim of the present study.

Our results demonstrate that male sex, being incarcerated and the presence of a psychiatric diagnosis are significant predictors of a recurrent foreign body event. Thus, once a foreign body ingestion has occurred, the presence of any of these factors should prompt a heightened awareness for an impending recurrent event. Possible explanations for recurrent ingestion in these patients likely involve issues of secondary gain, impulsivity or an underlying uncontrolled psychiatric disorder. In the prison population particularly, swallowing a foreign body can result in transfer to an offsite location, sometimes for several days. If the patient is then successfully treated for a foreign body ingestion with no downside, this behaviour may be repeated. In fact, our data only represents the prisoners who were sent to our hospital for endoscopic treatment for foreign body ingestion; thus, the true incidence of foreign body ingestion and, in turn, repeat ingestion in the prison population, is likely under-reported in the present study.

Motivation for recurrent ingestions in psychiatric patients is more difficult to discern, but it would seem logical to conclude that the more poorly controlled a patient's underlying psychiatric illness, the more likely they are to engage in repetitive abnormal and sometimes destructive behaviour. With a loss of impulse control, ingestion of dangerous foreign bodies may be similar to other self-destructive behaviours such as cutting, burning or ingesting toxic substances (14). If the patient is institutionalized, there also may be a degree of secondary gain by ingesting a foreign body and having the opportunity to leave the institution. Furthermore, a patient with psychiatric problems may experience worsening symptoms while in prison because of increased stressors or change in treatment.

Food impactions are often related to the presence of any type of esophageal pathology $(15-18)$. In the present study, the most common pathology leading to recurrent food impaction was a distal esophageal stricture, usually a reflux-related stricture or ring. Of the food impaction patients who underwent more than one endoscopy for a food impaction, $78 \%$ had some type of pathology noted on their endoscopic examination.

Even if the type of patients who ingest foreign bodies repeatedly can be identified, preventing recurrent ingestions is challenging because prevention occurs well before the patient encounters the 
hospital and gastroenterologist or endoscopist. The ability to identify factors before ingestion may allow for improvement in patient care. Options include altering the environment to decrease access to objects that can be swallowed or, for patients with psychiatric illness, change in medical regimen or more intensive psychotherapy. Individuals presenting with repeated food impactions may benefit from alteration in diet consistency, more frequently scheduled dilations or treatment of the underlying esophageal pathology that leads to the food impactions.

The present study also demonstrated that endoscopy in repeat ingestors can be performed successfully and with a low complication rate. Overall, the rate of successful endoscopic treatment in the recurrent foreign body ingestors was high (88\% [104 of 117]), but less when compared with single foreign body ingestion (97\% [111 of 114]) $(\mathrm{P}=0.02)$. When focusing on endoscopy for foreign objects alone, there was a trend toward decreased endoscopic removal success: $78 \%$ (49 of 63) for recurrent ingestors compared with 92\% (34 of 37) for single ingestors $(\mathrm{P}=0.09)$. Again, this showed that repeat ingestors tend to swallow more complicated, complex and sometimes multiple objects, which further stresses the need for preventive therapy. There was no difference in immediate procedure-related complications $(0 \%$ for recurrent ingestors compared with $2 \%$ for single ingestors $[\mathrm{P}=0.2])$, or need for eventual surgical intervention (four occasions [3\%] for recurrent ingestors compared with one occasion [0.8\%] for single ingestors $[\mathrm{P}=0.4])$. Complications in the single ingestor group included mild bleeding at the site of endoscopic removal with no serious sequelae. The data suggests that endoscopic removal should remain the initial treatment, even in the more complex, repeat true foreign body ingestors.

Repeat foreign body ingestors incur more medical costs on a per patient basis largely due to the need for repeat endoscopy (2.6 procedures

\section{REFERENCES}

1. Eisen GM, Baron TH, Dominitz JA, et al. Guideline for the management of ingested foreign bodies. Gastrointest Endosc 2002;55:802-6.

2. Lyons MF, Tsuchida AM. Foreign bodies of the gastrointestinal tract. Med Clin North Am 1993;77:1101-4.

3. Clerf LH. Historical aspects of foreign bodies in the food and air passages. South Med J 1975;68:1449-54.

4. Devanesan J, Pisani A, Sharman P, Kazarian KK, Mersheimer WL. Metallic foreign bodies in the stomach. Arch Surg 1977;112:664-5.

5. Velitchkov NG, Grigorov GI, Losanoff JE, Kjossev KT. Ingested foreign bodies of the gastrointestinal tract: Retrospective analysis of 542 cases. World J Surg 1996;20:1001-5.

6. Cheng W, Tam PK. Foreign-body ingestion in children: Experience with 1265 cases. J Pediatr Surg 1999;34:1472-6.

7. O'Sullivan ST, Reardon CM, McGreal GT, Hehir DJ, Kirwan WO, Brady MP. Deliberate ingestion of foreign bodies by institutionalized psychiatric hospital patients and prison inmates. Ir J Med Sci 1996;165:294-6.

8. Losanoff JE, Kjossev KT. Gastrointestinal crosses: An indication for surgery. J Clin Gastroenterol 2001;33:310-4.

9. Webb WA. Management of foreign bodies of the upper gastrointestinal tract: Update. Gastrointest Endosc 1995;41:39-51.

10. Vizcarrondo FJ, Brady PG, Nord HJ. Foreign bodies of the upper gastrointestinal tract. Gastrointest Endosc 1983;29:208-10. per patient) and the increased number of hospital admissions. Cost is increased because many of the recurrent ingestors have psychiatric problems and ingest multiple or complex objects. Palta et al (13) recently showed that patients admitted with intentional ingestions, particularly those with psychiatric problems, stay an average of six days in the hospital, further driving up cost of care. This obviously doubles and triples in patients who return to the hospital frequently with additional foreign body ingestions. By identifying patients who repeatedly return, preventive interventions may be possible, leading to considerable savings in health care costs.

Limitations of the present study include its small sample size and retrospective nature. The relatively small numbers make it possible that prisoner population and psychiatric diagnosis were overestimated. This series does, however, provide evidence that these associations exist and that consideration shuld be given to further treatment and modifications in this high-risk group.

\section{CONCLUSION}

Our study successfully identified risk factors to help predict patient groups at 'high risk' for recurrent foreign body ingestion. These factors include male sex, incarcerated status and the presence of psychiatric illness. Identifying these factors at the time of initial ingestion are important so that interventions to help minimize recurrence can be undertaken. Our study also showed that endoscopy can be performed successfully and safely in these patients, with little need for surgical intervention. Additional longitudinal studies on cost analysis and attempts at intervention (limiting patient access to dangerous foreign bodies, improved control of psychiatric illness) would be useful in determining societal impact and how best to prevent recurrence.
11. Nandi P, Ong GB. Foreign body of the esophagus: Review of 2394 cases. Br J Surg 1978;65:5-9.

12. Lee TH, Kang YW, Kim HJ. Foreign objects in Korean prisoners. Korean J Intern Med 2008;4:275-8.

13. Palta R, Sahota A, Bemarki A, Salama P, Simpson N, Laine L. Foreign body ingestion: Characteristics and outcomes in a lower socieoeconomic population with predominantly intentional ingestion. Gastrointest Endosc 2009;69:426-33.

14. Klonsky ED. The functions of deliberate self-injury: A review of the evidence. Clin Psychol Rev 2007;27:226-39.

15. Longstreth GF, Longstreth KJ, Yao JF. Esophageal food impaction: Epidemiology and therapy. A retrospective, observational study. Gastrointest Endosc 2001;53:193-8.

16. Katsinelos P, Kountouras J, Paroutoglou G, Zavos C, Mimidis K, Chatzimavroudis G. Endoscopic techniques and management of foreign body ingestion and food bolus impaction in the upper gastrointestinal tract: A retrospective analysis of 139 cases. J Clin Gastroenterol 2006;40:784-89.

17. Vicari JJ, Johanson JF, Frakes JT. Outcomes of acute esophageal food impaction: Success of the push technique. Gastrointest Endosc 2001;53:178-81.

18. Lacy PD, Donnelly MJ, McGrath JP, Byrne PJ, Hennessy TP, Timon CV. Acute food bolus impaction: Aetiology and management. J Laryngol Otol 1997;111:1158-61. 


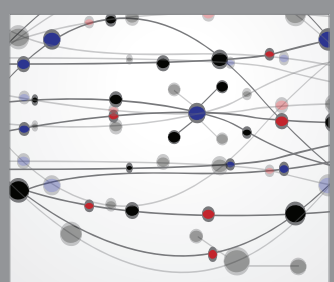

The Scientific World Journal
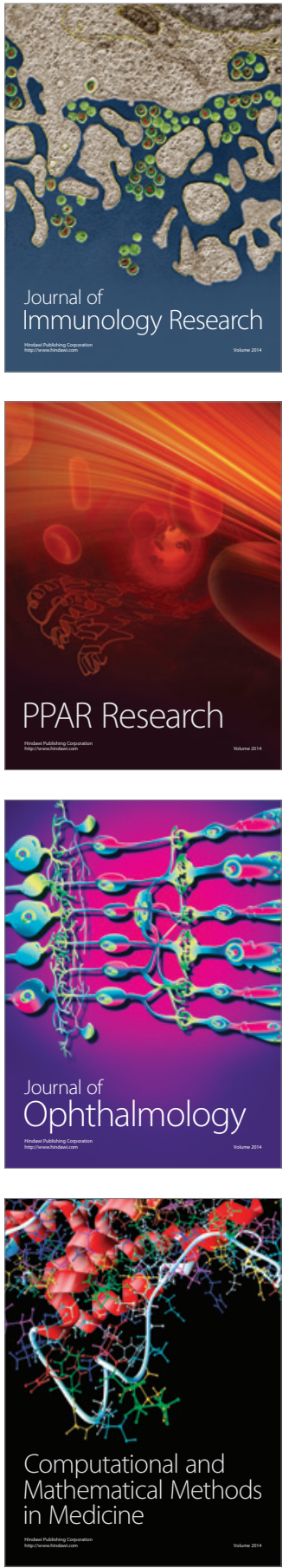

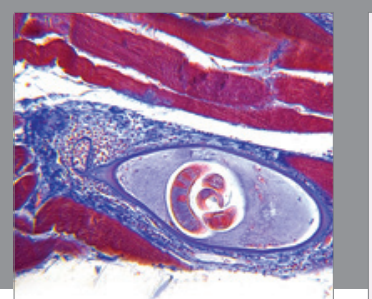

Gastroenterology Research and Practice

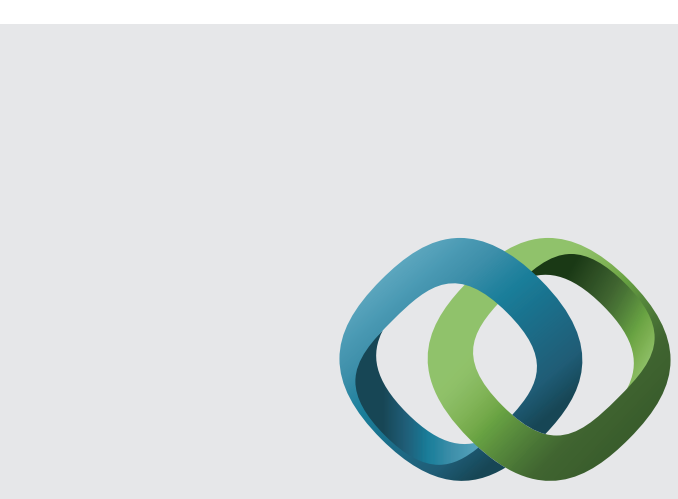

\section{Hindawi}

Submit your manuscripts at

http://www.hindawi.com
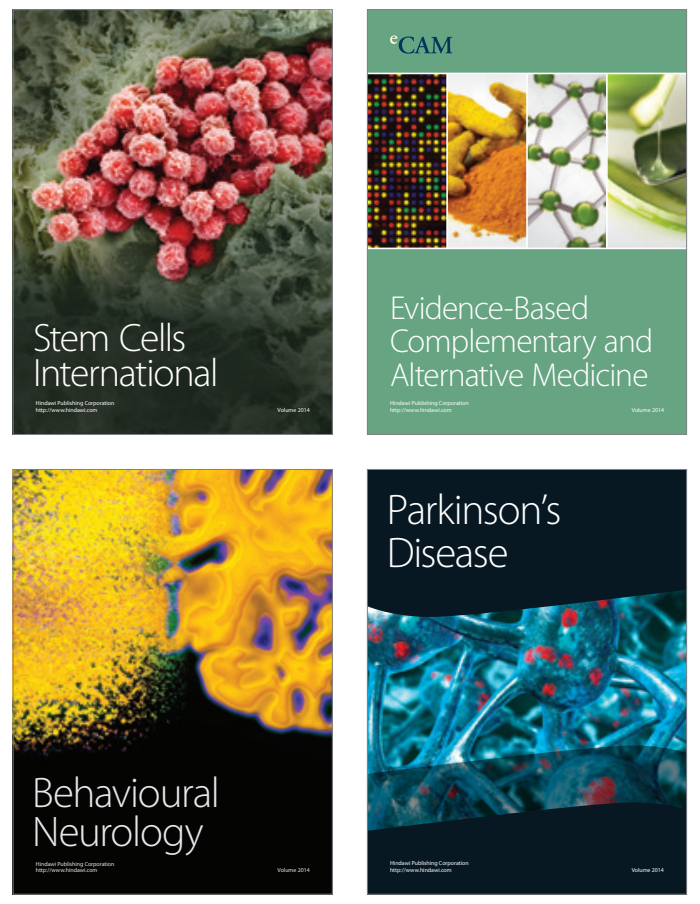
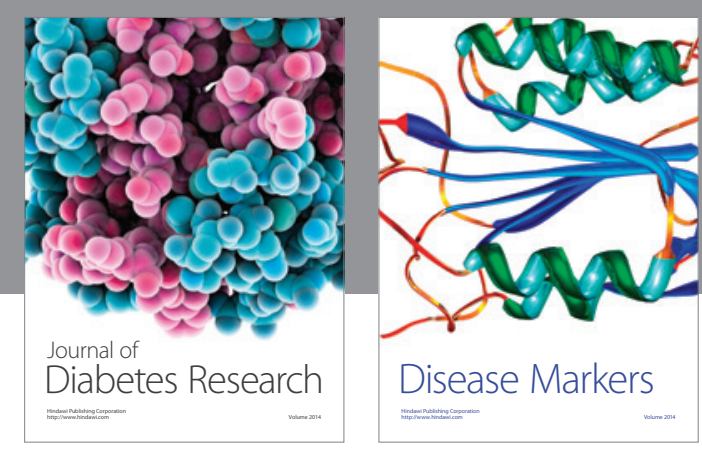

Disease Markers
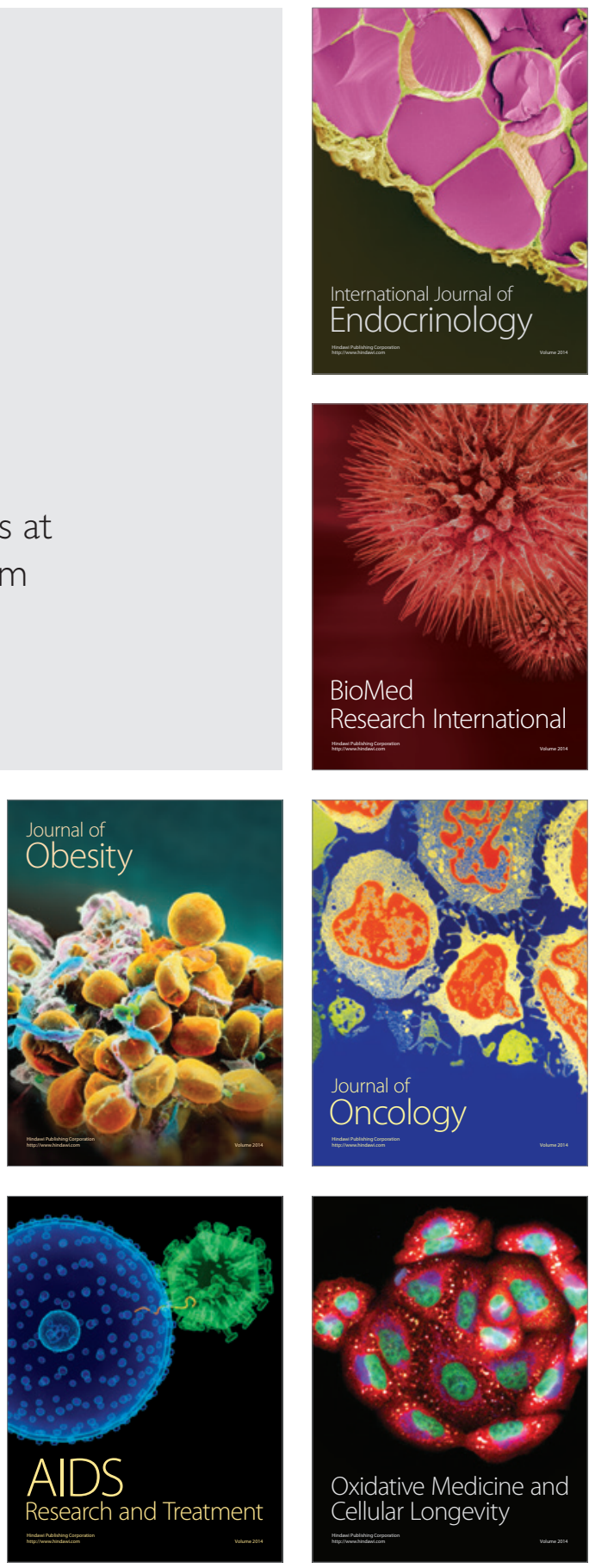